\title{
Experimental studies of combined coulter for direct strip sowing of seeds
}

\author{
Oleg Pisarev¹, Maksim Moskovskiy², Aleksey Dorockhov², Anatoly Gulyaev²,*, and \\ Aleksandr Lavrov ${ }^{2}$ \\ 1 LLC «POLIVPROEKT», prospect Kosmanavtov, 15, room CLII, city Korolev, Moscow \\ region141075, Russia \\ ${ }^{2}$ Federal Scientific Agro-Engineering Center VIM, 1 Institutsky proezd, 5, Moscow, 109428, Russia
}

\begin{abstract}
In the paper It is presented the results of experimental researches about determination of the main parameters of the seed distributer of the combined coulter for direct sowing of seeds at the installation for high-speed stroboscopic photography of particle movement.
\end{abstract}

\section{Introduction}

The most promising direction in the seeds sowing is development direct seeder with passive working bodies for Russian Federation conditions because of the higher reliability in operation, the relatively simple design and, accordingly, the lower cost in manufacturing for agricultural producer. At the same time, combined working bodies for direct sowing of cereals are promising in its development. They are ensured uniform distribution of seeds over the feeding area, and Researches of the type and justification of the main parameters of the combined coulter of the direct sowing seeder are actual tasks, ensuring the performance of high-quality strip sowing of cereals in compliance with agrotechnical requirements for zero tillage [1-6].

\section{Material and methods}

We had made experimentally justification of the construction parameters of the seed distributer of the combined coulter. For this we have studied the kinematics of particle motion along the working distributor surface by using high-speed stroboscopic photography of moving particles. We have made a laboratory installation for studying this process Figure 1. High-speed (stroboscopic) photography is an image on the single photofilm frame of a successive positions of moving object at regular intervals. The essence of the method is that the image of a moving particle is obtained simultaneously in two projections using one camera on the same frame.

The vertical projection of the motion trajectory is fixed by the photo camera in the lower half of the frame in the usual way, and rotating slotted disk is mounted in front of the

\footnotetext{
* Corresponding author: tomasss1086@mail.ru
} 
lens. A horizontal projection of the trajectory was obtained in the form of a mirror image on the upper half of the same frame using a mirror obliquely mounted over a moving particle.

The image is transferred to the computer and this image is decrypted by the AutoCad graphic editor. It is scaled to the actual size, which makes it possible to determine the range of the particle, the height of the trajectory, and also the speed of the particle by measuring the distance between two adjacent strokes of an intermittent path to meet it with a reflector and after leaving it

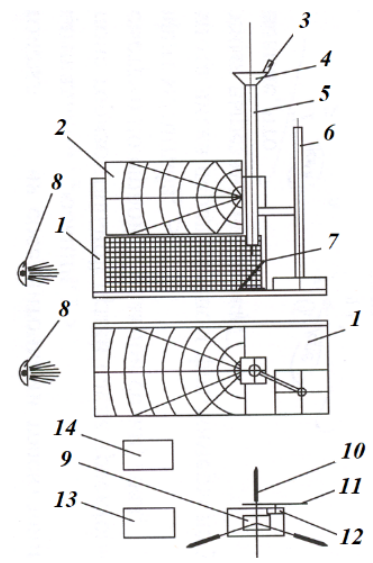

Fig. 1. Scheme of a laboratory installation for high-speed stroboscopic photography of particle movement: 1 is horizontal and vertical plane with coordinate grids; 2 is mirror; 3 is vibrator; 4 is loading hopper of seeds, 5 is seed tube; 6 is tripod, 7 is a seed reflector with a variable angle; 8 is illuminator; 9 is digital camera; 10 is camera tripod; 11 is a disk with cut rectangular holes; 12 is electric motor; 13 is electric motor control unit; 14 is digital tachometer for setting the speed of the disk.

The speed of particles before and after meeting with the working reflector surface is determined by the formula:

$$
v=0.001 l \cos \alpha k / t
$$

where $l$ is the distance between two adjacent points of the particle trajectory in vertical projection, $\mathrm{mm} ; \alpha$ is the angle of inclination of the horizontal projection of the trace of the trajectory relative to the axis of symmetry of the polar coordinate grid, deg; $\mathrm{k}$ is the coefficient of scale; $t$ is the time of disk rotation in front of the camera len at the angle between two adjacent cutouts on the disk, sec.

We determined the rational parameters of the distributor according to Figure 2. The main condition is ensuring the smallest loss of speed $\mathrm{v}_{0}$ and achieving a larger sieving width $b_{n}$..

For convenience of evaluating the choice of distributor parameters, we have determined the velocity conservation coefficient $(\mu)$, which is the ratio of the absolute particle velocities after $\left(\mathrm{v}_{0}\right)$ and before the meeting $\left(\mathrm{v}_{\mathrm{n}}\right)$ with the working surface, as the main criterion:

$$
\mu=\frac{v_{o}}{v_{n}} .
$$




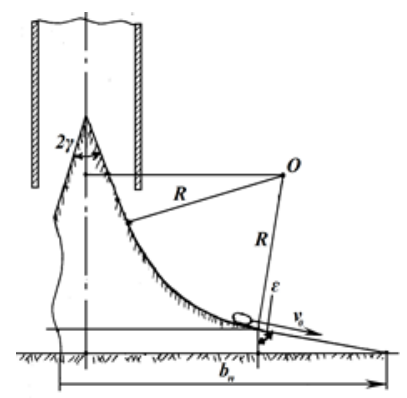

Fig. 2. Distributors scheme.

We installed a special device (Figure 3) under the seed tube 5 on the path of particle fall for conducting studies in the choice of the angle $2 \gamma$ in the installation of Figure 1.

This device was consisted of a stationary horizontal platform 1 and a working flat surface 4 pivotally mounting to it on axis 2 , which can be installed under different angle of inclination to the horizontal from 0 to $90^{\circ}$.

The device is equipped with a graduated scale 3 and a fixing screw. To determine the rational radius $\mathrm{R}$ of the distributor on the specified device on a flat surface 4 fixed at an angle $\beta$ of about $80^{\circ}$, alternately curved concave surfaces with different radius of curvature were installed.

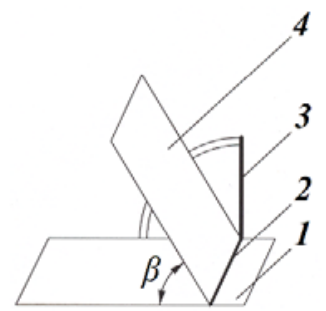

Fig. 3. Scheme of a device for studying the kinematics of particle motion at various angles of inclination of the working surface

Photographing of the particle motion reflected from the surface 4 was carried out at different inclination angles $\beta$. When decrypting the captured frames, the particle velocity was determined before and after hitting an inclined plane and the horizontal range of the particles.

The same was done with surfaces with different radius R. Investigations were carried out on the Figure 1. installation to determine the dependence of the width of the seeding strip on the angle of inclination of the tangent relative to the vertical to the particle trajectory when leaving the distributor wing.

\section{Results and discussion}

Figure 4 shows a fragment of a spatial high-speed stroboscopic photo of the trajectory of the movement of wheat seeds.

When determining the coefficient $\mu$ of conservation of speed it is established:

- the smallest loss in seed speed $(\mu>0.9)$ when encountered with the reflection plane occurs at angles $\beta \geq 78^{\circ}$ (or $\gamma \leq 12^{\circ}$ ).

- the highest value of the velocity conservation coefficient $(\mu=0.63)$ is achieved with a radius of curvature of the working surface $R=40 \mathrm{~mm}$, and the vanishing angle $\varepsilon=77^{\circ}$ Figure 5. 


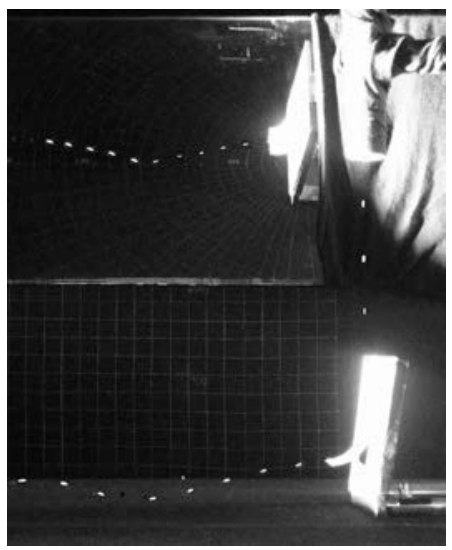

Fig. 4. Fragment of spatial high-speed photography of the particle trajectory along the surface of the distributor.

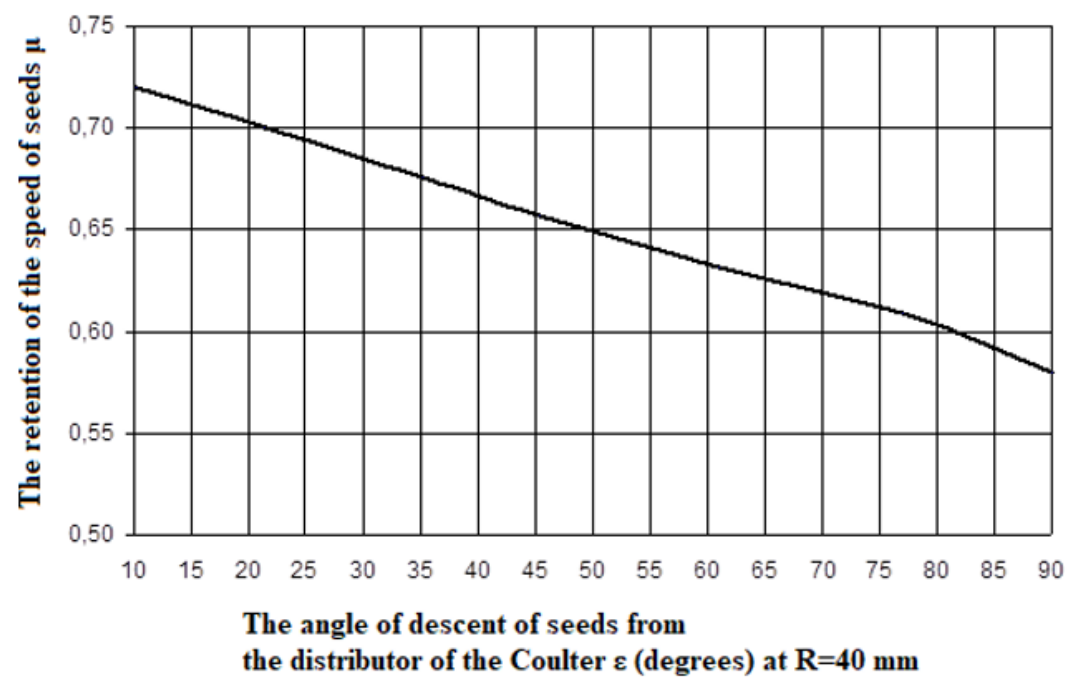

Fig. 5. Dependence of the coefficient of conservation of grain velocity $\mu$ on the angle of descent of the particle from the distributor $\varepsilon$ at $\mathrm{R}=40 \mathrm{~mm}$.

Based on the results of experimental studies, as well as subject to the conditions for the mutual placement of structural elements, the parameters of the distributor of the combined coulter:

- angle at the apex of the distributor $2 \gamma=24^{\circ}$;

- the radius of curvature of the working surface on the wings of the distributor $R=40$ $\mathrm{mm}$.

By analogy with the above, we performed an experiment on the same setup for high-speed stroboscopic photography to determine the dependence of the width of the seeding strip on the angle of inclination of the tangent relative to the vertical to the particle trajectory when leaving the distributor wing. As can be seen from the graph in Figure 6, depending on the values of the angle $\varepsilon$, the width of the seed sowing band varies significantly. At the same 
time, the width of the seeding strip within $150 \ldots 160 \mathrm{~mm}$ is achieved at an angle $\varepsilon=60^{\circ}$.

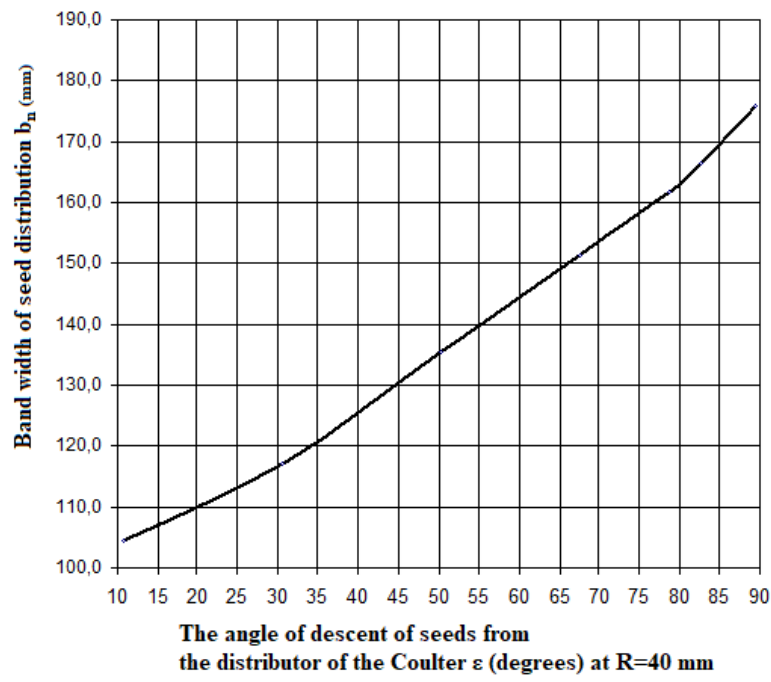

Fig. 6. Dependence of the width of the strip of seed distribution bn on the angle of descent from the distributor $\varepsilon$, at $\mathrm{R}=40 \mathrm{~mm}$

\section{Conclusion}

1. It was found that the width of the distribution band of seeds (wheat seeds) depends on the geometry of the distributor and the absolute velocity of the particles after meeting with the working surface.

2. The parameters of the distributor selected from the condition of ensuring the least loss of speed and width of the seed distribution strip bn $=160 \mathrm{~mm}$ are presented in Table 1 .

Table 1. Distributor parameters by results experimental research

\begin{tabular}{|l|c|}
\hline \multicolumn{1}{|c|}{ Distributor Parameters } & $\begin{array}{c}\text { Value } \\
\text { Parameter }\end{array}$ \\
\hline Width mm & 90 \\
\hline Length mm & 32 \\
\hline Height mm & 12 \\
\hline The angle at the vertex $\gamma, \mathrm{deg}$. & 77 \\
\hline The angle of descent $\varepsilon, \mathrm{deg}$. & 40 \\
\hline Radius of a circle R, mm. & 28 \\
\hline The length of the straight section, mm & 51 \\
\hline The length of the curved section, mm & 79 \\
\hline $\begin{array}{l}\text { The sweep length of the generatrix of the working surface, } \\
\text { mm }\end{array}$ & 48 \\
\hline $\begin{array}{l}\text { The distance from the soil surface to the center of the circle, } \\
\text { mm. }\end{array}$ & 49 \\
\hline $\begin{array}{l}\text { The distance from the axis of the distributor to the center of } \\
\text { the circle, mm }\end{array}$ & 46 \\
\hline $\begin{array}{l}\text { The angle of inclination of the edge to the longitudinal axis } \\
\text { of the opener, deg. }\end{array}$ & \\
\hline
\end{tabular}




\section{Reference}

1. A.Yu. Izmaylov. VIM: 85 years in the forefront of the domestic agricultural machinery engineering. Sel'skokhozyaystvennyye mashiny i tekhnologii, 2014; 6: 10-13. (in Rus.).

2. Izmailov A.Yu., Lobachevsky Y. P., Shaykhov MK, Shaykhov M.M. Grain seeders in a complex of machines for technologies for the restoration of degrading lands // Transactions of GOSNITI. 2017.V. 129. S. 219-228.

3. Sucheratin N.F. Energy conservation in direct sowing of grain crops // Actual directions of scientific research of the XXI century: theory and practice. 2014.V.2. N3-4 (8-4). S. 463-468.

4. Thompson Carlyle A., Whitney David A. Effects of 30 years of cropping and tillage systems on surface soil test changes // Commun. Soil Sciand Plant Anal. 2000. Vol. 31. N12. P. 241257.

5. Keller K. Agriculture without a plow. Preserving tillage and direct sowing // New Agriculture. 2002. No. 1. S. 2226.

6. Brisson, N., Gate, P., Gouache, D., Charmet, G., Oury, F.X. \& Huard, F. (2010). Why are wheat yields stagnating in Europe? A comprehensive data analysis for France. Field Crops Res. 119, 201-212, doi:10.1016/j.fcr.2010.07.012. 